\title{
Bioaugmented Mixed Culture by Clostridium aceticum to Manipulate Volatile Fatty Acids Composition From the Fermentation of Cheese Production Wastewater
}

OPEN ACCESS

Edited by:

Hyung-Sool Lee,

University of Waterloo, Canada

Reviewed by:

Yi Wang,

Auburn University, United States

Po-Heng Lee,

Imperial College London,

United Kingdom

*Correspondence:

Merve Atasoy

mervea@kth.se

Specialty section:

This article was submitted to

Microbiotechnology,

a section of the journal

Frontiers in Microbiology

Received: 08 February 2021

Accepted: 30 June 2021

Published: 03 September 2021

Citation:

Atasoy M and Cetecioglu Z (2021)

Bioaugmented Mixed Culture by

Clostridium aceticum to Manipulate

Volatile Fatty Acids Composition From

the Fermentation of Cheese

Production Wastewater.

Front. Microbiol. 12:658494.

doi: 10.3389/fmicb.2021.658494

\author{
Merve Atasoy* and Zeynep Cetecioglu \\ Department of Chemical Engineering, KTH Royal Institute of Technology, Stockholm, Sweden
}

Production of targeted volatile fatty acid (VFA) composition by fermentation is a promising approach for upstream and post-stream VFA applications. In the current study, the bioaugmented mixed microbial culture by Clostridium aceticum was used to produce an acetic acid dominant VFA mixture. For this purpose, anaerobic sequencing batch reactors (bioaugmented and control) were operated under $\mathrm{pH} 10$ and fed by cheese processing wastewater. The efficiency and stability of the bioaugmentation strategy were monitored using the production and composition of VFA, the quantity of C. aceticum (by qPCR), and bacterial community profile (16S rRNA Illumina Sequencing). The bioaugmented mixed culture significantly increased acetic acid concentration in the VFA mixture (from $1170 \pm 18$ to $122 \pm 9 \mathrm{mgCOD} / \mathrm{L}$ ) compared to the control reactor. Furthermore, the total VFA production (from $1254 \pm 11$ to $5493 \pm 36 \mathrm{mgCOD} / \mathrm{L}$ ) was also enhanced. Nevertheless, the bioaugmentation could not shift the propionic acid dominancy in the VFA mixture. The most significant effect of bioaugmentation on the bacterial community profile was seen in the relative abundance of the Thermoanaerobacterales Family III. Incertae sedis, its relative abundance increased simultaneously with the gene copy number of $C$. aceticum during bioaugmentation. These results suggest that there might be a syntropy between species of Thermoanaerobacterales Family III. Incertae sedis and C. aceticum. The cycle analysis showed that $6 \mathrm{~h}$ (instead of $24 \mathrm{~h}$ ) was adequate retention time to achieve the same acetic acid and total VFA production efficiency. Biobased acetic acid production is widely applicable and economically competitive with petroleum-based production, and this study has the potential to enable a new approach as produced acetic acid dominant VFA can replace external carbon sources for different processes (such as denitrification) in WWTPs. In this way, the higher treatment efficiency for WWTPs can be obtained by recovered substrate from the waste streams that promote a circular economy approach.

Keywords: volatile fatty acid, acetic acid, Clostridium aceticum, bioaugmentation, bacterial community profile, qPCR, cheese production wastewater, fermentation 


\section{INTRODUCTION}

The current size of global chemical production is unknown. In Europe, it was 330 million tons in 2007 (Eurostat, 2020), and is increasing by a $7 \%$ compound annual growth rate (UNEP, 2013) to meet the demands for industrial, agricultural, pharmaceutical applications. On the other hand, the adverse environmental effects of petroleum based production have resulted in an increase of $\mathrm{CO}_{2}$ emissions from two billion tons to over 36 billion tons in the last 115 years (Ritchie and Roser, 2019). Therefore, sustainable, environmentally friendly, and economically competitive bioproduction is a vital method in achieving Sustainable Development Goals (United Nations, 2018) and the targets of the Paris Agreement, (UNFCCC, 2015). One of the crucial methods of attaining sustainable bioproduction is transforming traditional wastewater treatment plants into biorefineries, that use waste streams as feedstock (Dietrich et al., 2017; Mussatto, 2017).

Several studies for biobased chemical production from waste streams have been conducted in recent years (Lu et al., 2019; Xie et al., 2019). Foremost among them, volatile fatty acid (VFA) is one of the most promising products because of its versatile usage area in post stream and upstream applications (Khan et al., 2016b; Atasoy et al., 2018). Nevertheless, low production efficiency, unstable VFA composition for upstream and post stream applications, complications in purification, and separation of the end products, post-process requirements, and high substrate cost, etc., limit the industrialisation of biobased VFA production. Various studies have been carried out to enhance biobased VFA production efficiency by optimizing operational and environmental conditions (Khan et al., 2016a; Bhatia and Yang, 2017; Atasoy et al., 2018; Fang et al., 2020). These studies showed that different parameters such as $\mathrm{pH}$, temperature, retention time, loading rate, reactor type, and mixing, etc., must be taken into account for efficient biobased VFA production.

The end product spectrum of VFA is another crucial factor in post stream and upstream applications. For example, acetic acid dominant VFA as a carbon source achieved the highest polyhydroxyalkanoates (PHA) production yield (Ciesielski and Przybylek, 2014; Kedia et al., 2014) and acetic acid has been used as an efficient carbon source for denitrification processes (Du et al., 2019). Furthermore, every industry has different feedstock requirements, for example, acetic acid has been extensively used in the polymer industry for the production of vinyl acetate monomer (Gunjan and Haresh, 2020). Thus, enhancement of specific acid concentration in the VFA mixture is preferred for easier separation/purification of the end product. For these reasons, the efficient and sustainable production of the desired acid composition is one of the primary research problems that need to be addressed in the commercialization of biobased VFA production. Therefore, the current study aimed to develop acetic acid dominant VFA mixture production.

Acetic acid comprises a large part of the VFAs market (Bhatia and Yang, 2017) and has been used as a vinyl acetate monomer, purified terephthalic acid, acetate esters, acetic anhydride in several industries such as chemical, food and beverage, inks, paints, and coatings, etc., (Vidra and Németh, 2018; Allied Market Research, 2020). The global acetic acid market is estimated to reach 20.3 million tons by 2024 (Expert Market Research, 2019). Nevertheless, more than $90 \%$ of acetic acid is produced synthetically (Atasoy et al., 2018). In several wastewater treatment plants, acetic acid has been used as a carbon source in the denitrification process (Mielcarek et al., 2018; Du et al., 2019). However, this acetic acid is mostly bought externally, which is obtained by petroleum-based methods. Furthermore, biobased acetic acid is approved and generally recognized as safe (GRAS) by the United States Food and Drug Administration (FDA, 1989) and has been preferred as a food additive (Younes et al., 2020). In this sense, biobased acetic acid production is essential to achieve sustainable and environmentally friendly chemical production. Accordingly, the current study aimed to produce an acetic acid dominant VFA mixture by the application of a bioaugmentation strategy.

Recent studies suggested that bioaugmentation is a successful strategy to not only enhance microbial community performance for obtaining desired products (Tang et al., 2019; Atasoy and Cetecioglu, 2020; Li et al., 2020; Wu et al., 2020) but also improve the microbial community and their interactions for better adaptations to various environmental conditions (Tabatabaei et al., 2020). Bioaugmentation is a promising approach by adding microorganisms externally to the existing microbial community for improving the degradation rate of the contaminants (Cirne et al., 2006), enhancing the production efficiency of specific products (Chi et al., 2018; Tabatabaei et al., 2020), reducing the inhibition effects of some substances in the process (Yang et al., 2019), which has been used to find a solution for several practical issues in wastewater treatment plants (Herrero and Stuckey, 2015; Hong et al., 2020). Yang et al. (2019) investigated the effects of bioaugmentation with several pure cultures on anaerobic digestion to improve biogas production via preventing ammonia inhibition (Yang et al., 2019). In anaerobic digestion, the microbial community is comprised of undefined mixed culture, which is robust and easy for operation; nevertheless, monoculture produces a specific product. Therefore, bioaugmentation is a promising strategy for developing a new microbial consortium for strong, higher productivity and open for manipulation to produce targeted product profiles.

Clostridium aceticum is the first isolated acetogen from soil, found by Wieringa in 1936 (Küsel and Drake, 2011). It is a well-known acetic acid producer bacteria (Braun et al., 1981). C. aceticum is strictly anaerobic and can grow both autotrophically and heterotopically (Poehlein et al., 2015). Because of its versatile growth ability, C. aceticum has been widely used for acetic acid production (Sim et al., 2007; Arslan et al., 2019; Riegler et al., 2019). In our previous study, we used C. aceticum for acetic acid production from semi-synthetic milk processing wastewater fermentation under alkali $\mathrm{pH}$ (Atasoy et al., 2020a). Therefore, C. aceticum is selected as pure culture in the current study to bioaugment mixed microbial culture for acetic acid dominant VFA mixture.

Although different types of waste streams have been used for acetic acid production via fermentation, one of the most promising waste streams comes from dairy industry, which 
has a massive wastewater production volume (Hansen, 1974) with a rich carbohydrate, protein, and fat content (Britz and van Schalkwyk, 2006). Lagoa-Costa et al. (2020) showed that cheese whey has great potential for VFA production as a substrate because it includes more than $90 \%$ of easily degradable compounds. Their results stated that acetic acid concentration in VFA mixture from cheese whey fermentation at acidogenic $\mathrm{pH}$ was almost similar under different retention times, food/microorganism (F/M) ratios, and sludge retention times (SRTs), despite the degree of acidification and the acidification yield was changed under different conditions. On the other hand, Jankowska et al. (2017) showed the effects of various $\mathrm{pH}$ on VFA composition from cheese whey fermentation: acetic acid production was around $20 \%$ under acidic $\mathrm{pH}$ and approximately $40 \%$ without $\mathrm{pH}$ adjustment (neutral $\mathrm{pH}$ ), whereas, it was more than 91\% under alkali pH (Jankowska et al., 2017). Atasoy et al. (2019a) stated that higher acetic acid concentration was obtained from the monoculture (C. aceticum) (743 mg COD/L) than mixed culture (541 mg COD/L) from milk processing wastewater fermentation under alkali pH (Atasoy et al., 2019a). As previously stated, various waste streams as substrate provide an excellent opportunity for acetic acid and VFA production via fermentation. Nevertheless, further studies are required to increase the production yield for economically competitive and sustainable VFA production from waste streams.

In the current study, enhancement of acetic acid in VFA mixture was aimed by bioaugmentation. With this approach, the produced acetic acid dominant VFA mixture could be used in different processes (such as denitrification) as a carbon source to achieve a circular economy approach in WWTPs. In this regard, the mixed culture is bioaugmented by $C$. aceticum. Cheese production wastewater was used as a substrate to integrate the bioaugmentation strategy into industrial waste streams. The long term ASBR was operated under alkali $\mathrm{pH}$ to investigate the effects of the bioaugmentation. The bacterial community profile was analyzed by $16 \mathrm{~S}$ rRNA sequencing and C. aceticum was quantified by quantitative realtime polymerase chain reaction (qPCR). Cycle analysis was also conducted to investigate the effects of bioaugmentation on acid composition.

\section{MATERIALS AND METHODS}

\section{Substrate and Inoculum}

Cheese production wastewater was used as a substrate in all reactors. The wastewater was taken from the cheese production industry, which is located in Sweden. The wastewater included $20000 \pm 60 \mathrm{mg} \mathrm{COD} / \mathrm{L}, 200 \mathrm{mg} / \mathrm{L}$ total nitrogen, $18 \mathrm{mg} / \mathrm{L}$ total phosphate, and $11 \mathrm{mg} / \mathrm{L}$ orthophosphate. The wastewater contained $14.26 \pm 6 \mathrm{mg}$ COD/L VFA and $0.22 \pm 0.08 \mathrm{mg} \mathrm{COD} / \mathrm{L}$ lactic acid. The medium, vitamin, and trace element solutions were prepared according to the OECD 311 (OECD, 2003) and used for pure culture incubation. The medium and trace element solution was autoclaved separately for $30 \mathrm{~min}$ at $121^{\circ} \mathrm{C}$. The vitamin solution was also filtered through a membrane filter with a $0.22 \mu \mathrm{m}$ pore size filter for sterilization.

\section{Mixed Culture}

The granular seed sludge $(\approx 3.5 \mathrm{~mm}$ with $43 \%$ total solids (TS) and volatile solids (VS) 30\%) were used as a mixed culture, which was collected from the UASB reactor at Hammarby Sjöstadsverk Pilot Plant, Stockholm, Sweden. It was stored at $+4^{\circ} \mathrm{C}$ until the experiments were set up. The detailed characterization of granular seed sludge was described by Atasoy et al. (2019b).

\section{Monoculture}

The bioaugmentation of mixed culture was applied by C. aceticum (No. 1496, DSMZ, Germany) to enhance acetic acid production in mixed culture fermentation. The monoculture was grown in YPD Liquid Media (VWR Life Science, Sweden) at $32.5^{\circ} \mathrm{C}$ in an incubator with $120 \mathrm{rpm}$ mixing for $36 \mathrm{~h}$ under anaerobic conditions. Before bioaugmentation, the monoculture was cultivated with the substrate to observe and evaluate their growth and interactions. The growth of monoculture was observed by using OD600. The pure culture from the actively growing culture (the OD600 was 2.0) was used for bioaugmentation. In addition, approximately $50 \mathrm{~mL}$ (aliquoted $5 \mathrm{~mL}$ ) of pure culture was stored in glycerol (50\% as volume) at $-80^{\circ} \mathrm{C}$ for further usage.

\section{Reactor Design and Operation}

The AMPTS II System (Bioprocess Control, Sweden) was used for an anaerobic sequencing batch reactor which had $1400 \mathrm{~mL}$ active volume, $2000 \mathrm{~mL}$ total volume. The reactors were operated by cycling through a sequence of four phases in a single reaction vessel, the detailed operation of the reactors was presented in Figure 1. The system was mixed continuously at $120 \mathrm{rpm}$ under $35^{\circ} \mathrm{C}$ and $\mathrm{pH} 10 \pm 0.5$, which was adjusted using $2 \mathrm{M} \mathrm{NaOH}$.

The reactors were fed in a stepwise manner with different organic loading rates (OLR) which are explained in detail in Atasoy et al. (2020a). In steady-state conditions (based on influent and effluent chemical oxygen demand (COD) concentrations), the bioaugmentation was applied with a $0.6 \mathrm{~F} / \mathrm{M}$ ratio. The SRT was 35 days, calculated according to the VS loss during decanting. The hydraulic retention time (HRT) was 3.5 days.

\section{Cycle Analysis}

The cycle analysis was conducted to observe the bioaugmentation effects on VFA composition shift during a cycle, which was carried out after 7 days the bioaugmentation was completed in each reactor. The samples were taken in each hour during one cycle $(24 \mathrm{~h})$ as well as before $(-1$ st hour) and after feeding (0th hour).

\section{Bioaugmentation Strategy}

The bioaugmentation strategy was applied as explained by Atasoy and Cetecioglu (2020). It included three main phases; Phase A: before bioaugmentation (steady-state conditions based on COD concentration), Phase B: during bioaugmentation (the monoculture was added to the bioaugmented reactor in each cycle for 7 days as $10 \%$ of the reactor volume), and Phase C: after bioaugmentation (the reactors were operated for two sludge ages to observe the growth of monoculture in mixed culture). 


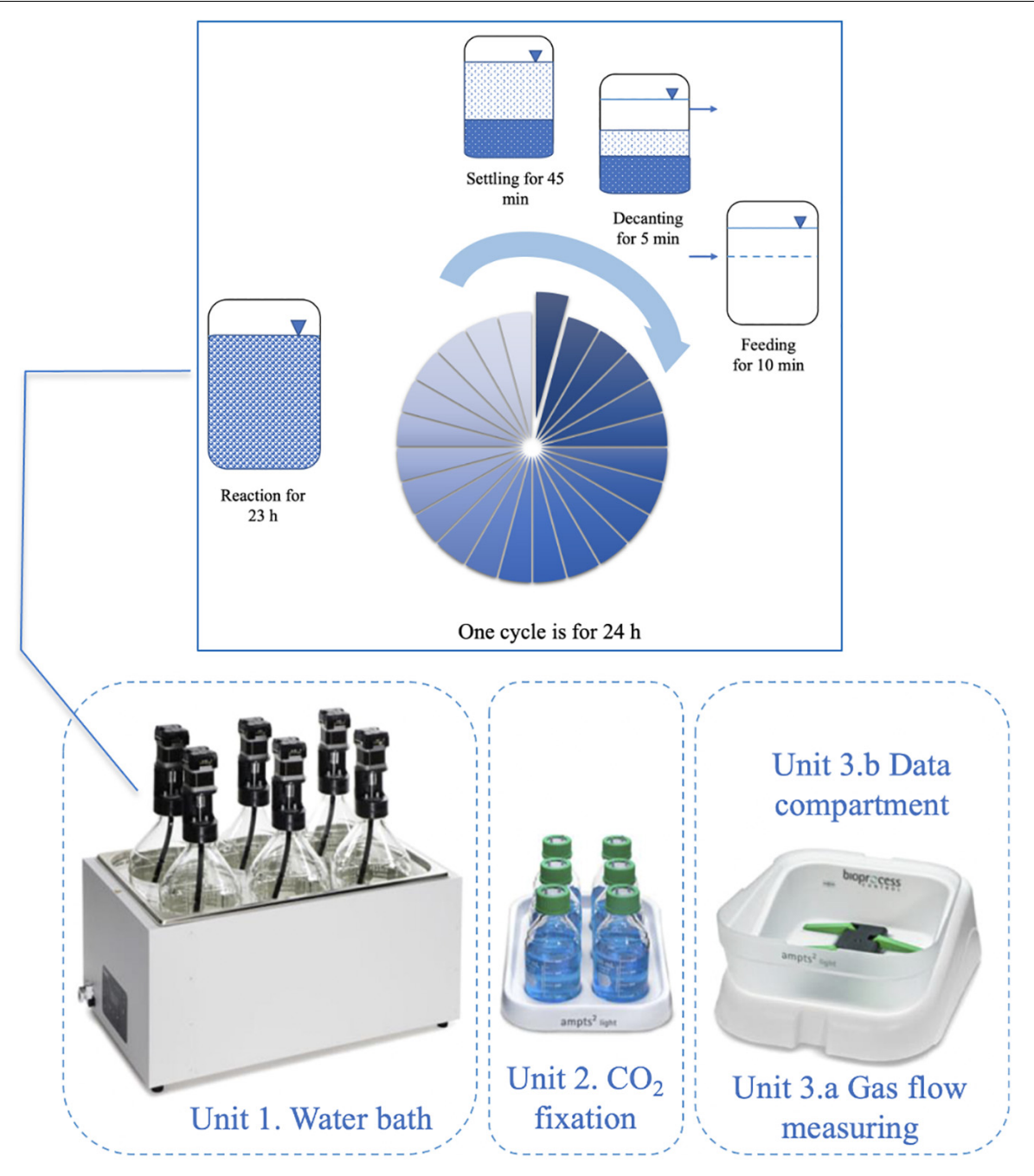

FIGURE 1 | The AMPTS II System (Bioprocess Control, Sweden) for anaerobic sequencing batch reactors and detailed operation regime.

\section{Analytical Methods}

During the whole operation, Total COD (TCOD), soluble COD (SCOD), organic acids, VFA compositions, and $\mathrm{pH}$ were monitored in both influent and effluent of the reactor. The COD equivalent of each VFA was calculated to validate the mass balances derived. The SCOD/TCOD, organic acids, total Nitrogen, and Phosphorus were measured using LCK 514 COD (100-2000 mg/L), organic acids LCK 365 Organic Acids (50-2500 mg/L), LCK 238 total Nitrogen (5-40 mg/L TN), and LCK 348 Phosphate (Orto + total) (0.5-5 mg /LPO4 P) (Hach Lange, United States) cuvette tests by Hach Lange DR 3900 spectrophotometer. Also, TS and VS of the sludge were measured according to the Standard Methods (APHA et al., 2012). The concentration and composition of VFA (formic, acetic, butyric, propionic, valeric, isovaleric, hexanoic, and heptanoic acids) in the effluents were analyzed by gas chromatography (GC 6890, Agilent) with a flame ionization detector, as described in the previous study (Atasoy et al., 2019b). Biomethane production (BMP) was monitored during operation, nevertheless, a negligible amount of biomethane was produced because of alkali $\mathrm{pH}$. Therefore, the biomethane data did not present in the results. During and after the feeding of the reactors, the reactors flushed with nitrogen gas to enable anaerobic conditions.

\section{Bacterial Community Analysis}

The bacterial community profile was analyzed by $16 \mathrm{~S}$ rRNA gene sequencing. Total genomic DNA from $0.5 \mathrm{~g}$ samples with three replicates were isolated using NucleoSpin Soil Kit, (MachereyNagel, Germany) following the manufacturer's instructions. The bacterial 16S rRNA gene was amplified using primers 516F (5' to $3^{\prime}$ : TGC CAG CAG CCG CGG TAA) and 806R (5' to 3': GGA CTA CHV GGG TWT CTA AAT) (Caporaso et al., 2011; Klindworth et al., 2013). The PCR amplification conditions, purification and quantification of the PCR products, and preparation of the sequencing libraries were followed by Atasoy et al. (2019b). The samples were sequenced using the Illumina MiSeq platform by Science for Life Laboratory, the 
National Genomics Infrastructure, NGI (Sweden). Biophyton 1.78 was used to merge and quality filter the sequence data as well as to assign taxonomies at $97 \%$ similarity cut-off value (Cock et al., 2009). Raw sequence data is available at NCBI (project no. of PRJNA667606).

\section{Quantification of Clostridium aceticum}

The C. aceticum was quantified by using quantitative real-time polymerase chain reaction (qPCR) by using total genomic DNA. For the DNA extraction, $0.5 \mathrm{~g}$ samples as triplicate were isolated by using NucleoSpin Soil Kit, (Macherey-Nagel, Germany). The concentration of the extracted DNA was measured by fluorimetry using Qubit dsDNA HS Assay Kit (Invitrogen, Thermo Fisher Scientific, North America).

Quantitative real-time polymerase chain reaction was performed by using Applied Biosystems ${ }^{\circledR}$ QuantStudio ${ }^{\circledR} 3$ RealTime PCR System Thermo Fisher Scientific (United States). For each PCR run with PowerUp SYBR Green Master Mix, Applied Biosystems (Thermo Fisher Scientific Co., United States) detection, a melting curve analysis was performed to confirm the specificity in each reaction tube by the absence of primer-dimers and other nonspecific products. Reactions for all samples were shown to have only one melting peak, which indicated a specific amplification, making it suitable for accurate quantification. Controls were included for each PCR run during the analyses. At the end of the reactions, melting curve analyses were applied to confirm the absence of primer dimers and nonspecific products.

The primer for the quantification of C. aceticum sets targeting formyltetrahydrofolate synthetase gene (fhs) fhs1 (GTW TGG GCW AAR GGY GGM GAA GG) and fhs2 (GAR GAY GGW TTT GAY ATY AC) (Xu et al., 2009). Although fhs gene encoding 10-formylte- tetrahydrofolate synthetase is used for quantification of authentic acetogenic bacteria (De Vrieze and Verstraete, 2016), it was used to quantify C. aceticum in the current study, since the bioaugmentation was applied by using a specific strain. Standard curves were obtained for QPCR constructed from PCR products of C. aceticum by using a 10-fold dilution series, separately. Standard curves were constructed in each PCR run, and the copy numbers of the genes in each sample were interpolated using these standard curves.

\section{Calculation of Products Yield}

Acetic acid production yield ( $\mathrm{Y}_{\text {acetic }}$ ) (Eq. 1) and total VFA production yield $\left(\mathrm{Y}_{V F A}\right)$ (Eq. 2) were calculated as the ratio of acid concentration to the consumed COD concentration (Jankowska et al., 2017; Atasoy et al., 2020a).

$$
\begin{aligned}
Y_{\text {acetic }} & =\frac{C_{\text {acetic }}}{C_{\text {CODconsumed }}} \\
Y_{V F A} & =\frac{C_{V F A}}{C_{C O D c o n s u m e d}}
\end{aligned}
$$

where, $\mathrm{C}_{\text {acetic }}$ is the acetic acid concentration $(\mathrm{g} C O D / \mathrm{L})$ in the effluent, $\mathrm{C}_{\mathrm{VFA}}$ is the total VFA concentration $(\mathrm{g} \mathrm{COD} / \mathrm{L}$ ) in the effluent and $\mathrm{C}_{\mathrm{COD}}$ consumed is the consumed COD concentration $(\mathrm{g} \mathrm{COD} / \mathrm{L})$.

\section{Statistical Analysis}

All experiments were conducted in triplicate, the standard deviation of the average results was calculated. Additionally, Pearson's correlation analysis was conducted to identify the relationship between the quantification of monocultures and each acid type production. All statistical analysis was performed using IBM SPSS Statistics, Version 25.0.

\section{RESULTS AND DISCUSSION}

The effects of bioaugmentation on both the acetic acid production efficiency and total VFA production and acid composition were evaluated, separately. The assessment of acetic acid production efficiency was performed based on acetic acid concentration and quantification of C. aceticum, before, during and after the bioaugmentation. Additionally, the quantification of C. aceticum was correlated with the concentration of each acid type to investigate the effects of bioaugmentation regarding VFA composition from the mixed culture fermentation. Also, the cycle analysis to observe the shift of acids type during a cycle (24-h) was conducted.

\section{Acetic Acid Dominant VFA Production}

The acetic acid concentration in the bioaugmented and the control reactor with the gene copy number of the C. aceticum is represented in Figure 2, regarding before bioaugmentation (Phase A), during bioaugmentation (Phase B), and after bioaugmentation (Phase $\mathrm{C}$ ). The average acetic acid concentration before bioaugmentation (Phase A) was $88 \pm 23 \mathrm{mg}$ $\mathrm{COD} / \mathrm{L}$ in the bioaugmented reactor, while it was $96 \pm 29 \mathrm{mg}$ $\mathrm{COD} / \mathrm{L}$ in the control reactor. During bioaugmentation (Phase $\mathrm{B})$, the concentration was $287 \pm 102 \mathrm{mg} \mathrm{COD} / \mathrm{L}$ in the bioaugmented reactor, $156 \pm 43 \mathrm{mg} \mathrm{COD} / \mathrm{L}$ in the control reactor. After bioaugmentation was completed, the acetic acid concentration increased to $836 \pm 261 \mathrm{mg} \mathrm{COD} / \mathrm{L}$ in the bioaugmented reactor, while it was $200 \pm 87 \mathrm{mg}$ COD/L in the control reactor. The results showed that the average acetic acid production was increased almost four times by bioaugmentation of $C$. aceticum. The maximum acetic acid production was $1170 \pm 18 \mathrm{mg} C O D / L$ at day 63 in the bioaugmented reactor; it was $122 \pm 9 \mathrm{mg} \mathrm{COD} / \mathrm{L}$ in the control reactor. Based on the maximum acetic acid production, the concentration increased by almost 10 times in the bioaugmented reactor than in the control reactor.

The effects of bioaugmentation on acetic acid production were evaluated based on the literature studies as summarized in Table 1. For instance, Lagoa-Costa et al. (2020) used cheese whey for VFA production from acidogenic fermentation under different retention times and $\mathrm{F} / \mathrm{M}$ ratios. In their study, the highest acetic acid concentration was obtained as $3580 \mathrm{mg}$ COD/L from $55000 \mathrm{mg}$ COD/L substrate concentration, regardless of operational parameters (Lagoa-Costa et al., 2020). In another study, the highest acetic acid concentration $(5500 \pm 70 \mathrm{mg} \mathrm{COD} / \mathrm{L})$ was obtained by lettuce fermentation (SCOD content of substrate was $35700 \mathrm{mg}$ COD/L) under acidic $\mathrm{pH}(6 \pm 0.4)$ from the evaluation of VFA production 


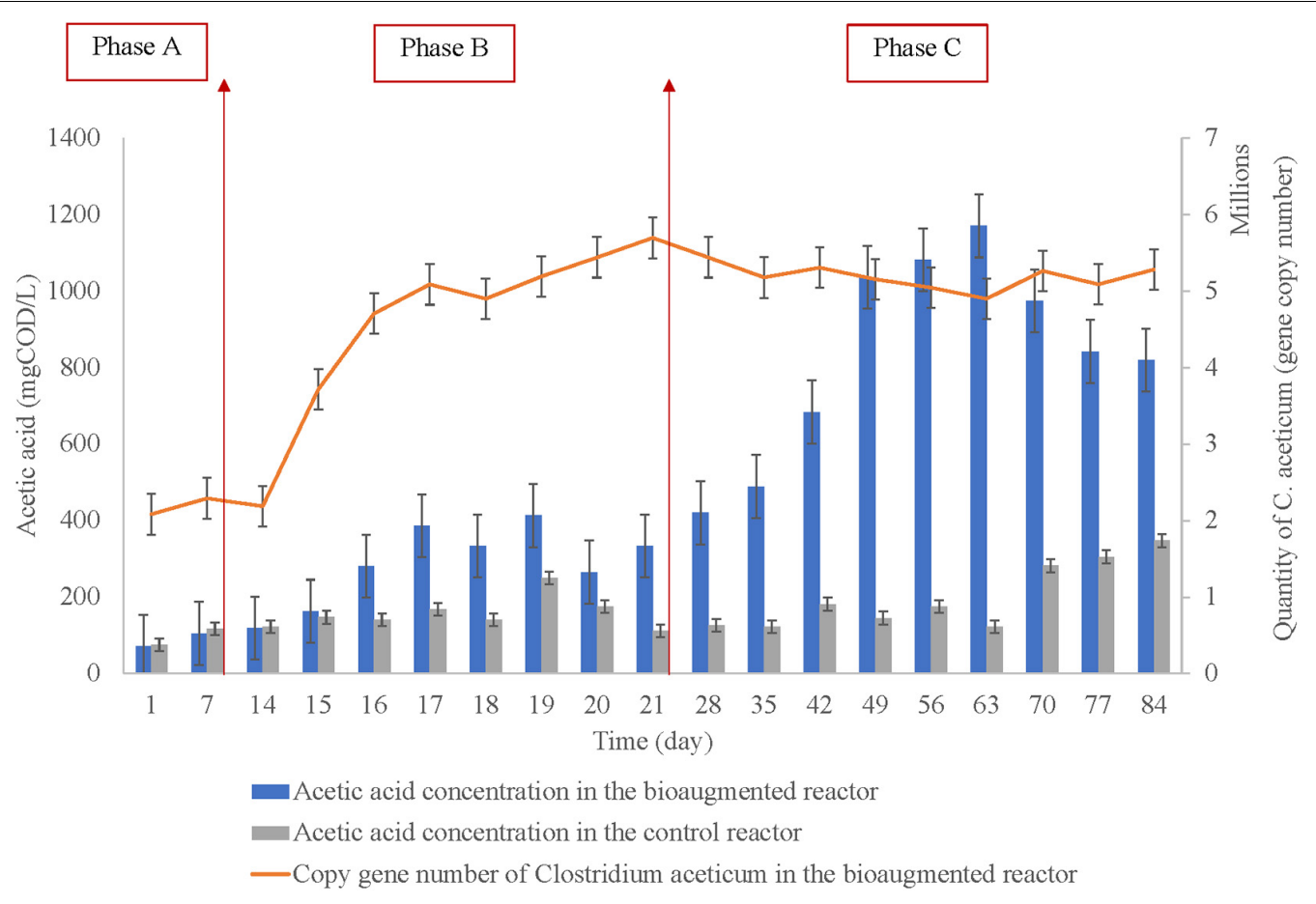

FIGURE 2 | The acetic acid concentration in the control and the bioaugmented set and quantification of Clostridium aceticum in the bioaugmented set (Phase A: before bioaugmentation; Phase B: during bioaugmentation, and Phase C: after bioaugmentation).

feasibility from agro-industrial waste (cucumber, tomato, and lettuce) (Greses et al., 2020). Lim et al. (2020) investigated VFA production from fermentation of palm oil mill effluent under $\mathrm{pH}$ 5 (Lim et al., 2020). Their results stated that the highest acetic acid concentration was obtained as $918 \mathrm{mg}$ COD/L at day 30 from $33400 \mathrm{mg}$ COD/L content of the substrate. She et al. (2020) used the pretreatment (freezing/thawing) for VFA production from waste activated sludge. The pretreatment increased the acetic acid production from $933 \pm 46$ to $1281 \pm 57 \mathrm{mg}$ COD/L as maximum concentration (the SCOD concentration of substrate was $5852 \mathrm{mg} / \mathrm{L}$ ) (She et al., 2020). From the view of substrate concentration in terms of COD content, the bioaugmentation of C. aceticum enhanced acetic acid production via fermentation more than 10 times than other studies. Based on the calculation of acetic acid production yield, it was $0.05 \mathrm{gCOD} / \mathrm{gCOD}$ at Phase A, $0.125 \mathrm{gCOD} / \mathrm{gCOD}$ at Phase B, and $0.181 \mathrm{gCOD} / \mathrm{gCOD}$ at Phase $\mathrm{C}$, respectively in the bioaugmented reactor with the $0.21 \mathrm{gCOD} / \mathrm{gCOD}$ (day 63) maximum value. Nonetheless, it was $0.06 \pm 0.02 \mathrm{~g} \mathrm{COD} / \mathrm{gCOD}$ as an average at the control reactor in all phases. The bioaugmentation of $C$. aceticum increased acetic acid production yield 3.5 times than the control reactor. Jankowska et al. (2017) stated that the acetic acid production yield from cheese whey fermentation varied under different $\mathrm{pH}$ : as an average acetic acid production yield was $0.056 \mathrm{gCOD} / \mathrm{gCOD}$ under acidic $\mathrm{pH}, 0.31 \mathrm{gCOD} / \mathrm{gCOD}$ under alkali $\mathrm{pH}$, and $0.164 \mathrm{gCOD} / \mathrm{gCOD}$ under neutral $\mathrm{pH}$.

Atasoy et al. (2019a) compared acetic acid production efficiency from monoculture and mixed culture during fermentation of milk processing wastewater under alkali
pH. Higher acetic acid concentration was obtained from C. aceticum as $743 \mathrm{mg}$ COD/L than the mixed culture as $541 \mathrm{mg}$ COD/L (Atasoy et al., 2019a). The result of the current study showed that bioaugmentation of mixed culture with $C$. aceticum produced almost two times higher acetic acid concentration than monoculture fermentation. Talabardon et al. (2000) evaluated the acetic acid production from milk permeate under thermophilic $\left(60^{\circ} \mathrm{C}\right)$ fermentation. Although many thermophilic acetogens are not able to ferment lactose, they investigated that Clostridium thermolacticum can convert lactate to acetate, ethanol, $\mathrm{CO}_{2}$ and $\mathrm{H}_{2}$ (Talabardon et al., 2000). From this point of view, our results stated that $C$. aceticum not only grew with cheese production wastewater as substrate but also it increased acetic acid production in mixed culture.

\section{Quantification of Clostridium aceticum During the Reactor Operation}

The efficiency of the bioaugmentation was monitored via acetic acid production and the adaptation of $C$. aceticum in the mixed culture. For this reason, C. aceticum was quantified in every phase during the operation, as represented in Figure 2. The results showed that the average gene copy number of $C$. aceticum was $2.2 \times 10^{6} \pm 1.5 \times 10^{3}$ before bioaugmentation (Phase $\mathrm{A}$ ), while it increased $4.6 \times 10^{6} \pm 1.1 \times 10^{4}$ during the application of bioaugmentation (Phase B). After the bioaugmentation was complete (Phase $\mathrm{C}$ ), the gene copy number increased $5.3 \times 10^{6} \pm$ $1.6 \times 10^{3}$ on average. Based on the quantification of C. aceticum, the average copy gene number increased almost 2.5 times by 
TABLE 1 | Acetic acid production by mixed microbial culture fermentation under various operational and environmental conditions.

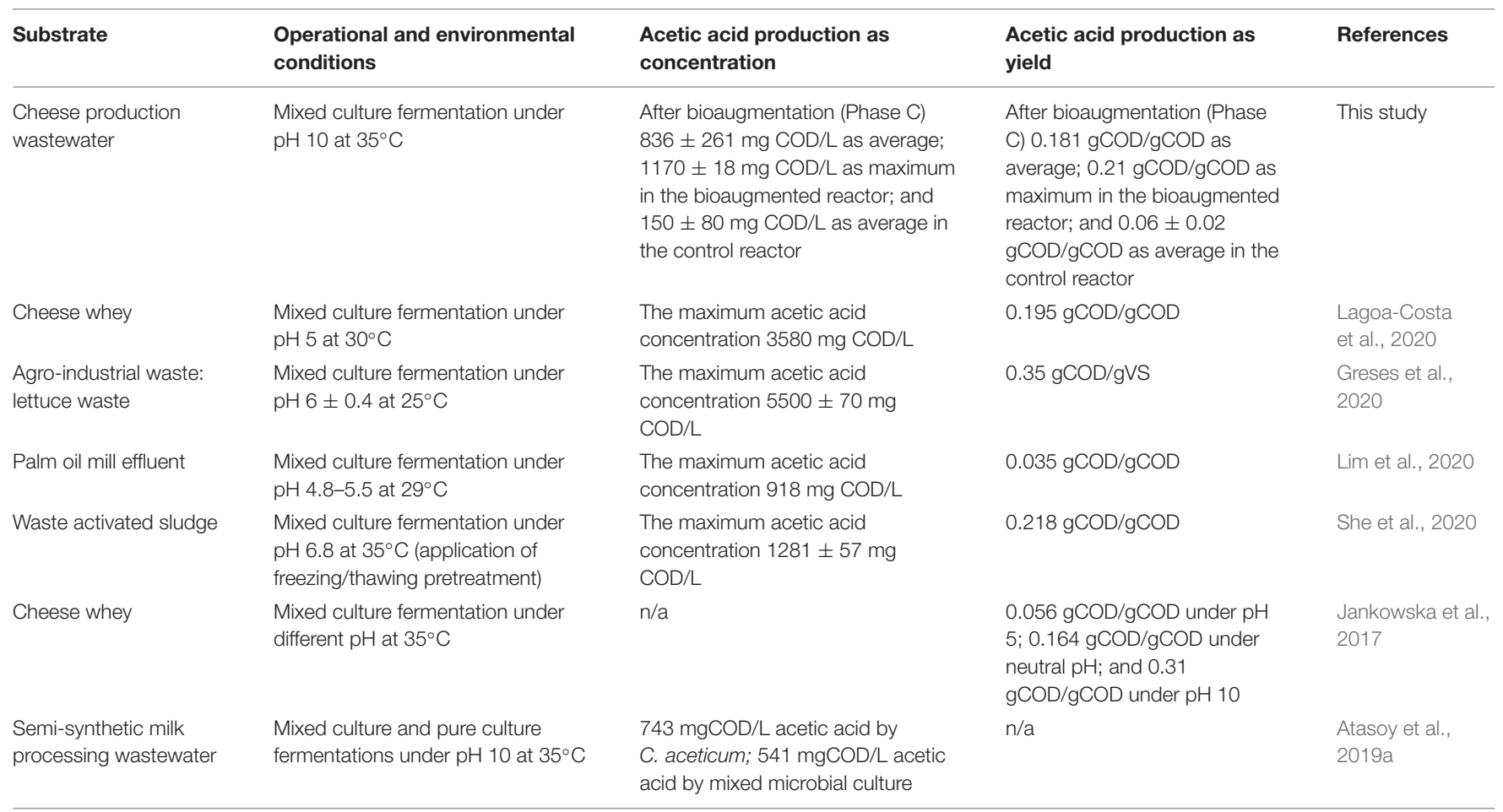

bioaugmentation. The highest gene copy number was obtained on day 21 as $5.7 \times 10^{6} \pm 1.2 \times 10^{2}$. Nevertheless, as stated before, the highest acetic acid production was obtained at day 63 .

Even though the main product of $C$. aceticum is acetic acid, there are several other products such as ethanol, butyric acid, and acetone etc., based on the metabolic pathway type (Jones et al., 2016). Arslan et al. (2019) investigated acetic acid and ethanol production by $C$. aceticum under acidic and alkali $\mathrm{pH}$ conditions (Arslan et al., 2019). Their results showed that C. aceticum had a fast biomass growth under $\mathrm{pH} 8$ with $1.8 \mathrm{~g}$ acetic acid production in the first $44 \mathrm{~h}$ of the fermentation. Nevertheless, the biomass growth of $C$. aceticum gradually decreased when the $\mathrm{pH}$ reached acidic conditions. Additionally, they observed that C. aceticum converted ethanol to acetic acid in the solventogenic phase as a reverse reaction (Arslan et al., 2019). From the perspective of their results, the growth of C. aceticum in the mixed culture might be promoted by the alkali $\mathrm{pH}$. The reverse reaction ability of $C$. aceticum could result in higher other acid types of production at $C$. aceticum in the bioaugmented reactor than the control reactor.

Clostridium aceticum has been studied mainly for autotrophic growth on carbon dioxide, carbon monoxide, and hydrogen gasses to produce acetic acid (Sim et al., 2007; Riegler et al., 2019). Nevertheless, the results of the current study revealed that C. aceticum adapted well to the mixed culture under high alkali $\mathrm{pH}$ (10) in carbon-rich substrate fermentation.

\section{Bacterial Community Profile}

Besides the quantification of $C$. aceticum, the bacterial community profile in the bioaugmented reactor was analyzed.
Analysis of the sequencing data for each phase (Phase A, B, and $\mathrm{C}$ ) were presented as phylum and family levels in Figure 3. The results showed that despite the most dominant phylum, members were the same in each phase (Figures 3A,C,E). Their relative abundance varied depending on the bioaugmentation stage. The most dominant phylum was Bacteroidetes in Phase A $(53 \pm 12 \%)$, while its relative abundance decreased to $37 \pm 9$ and $38 \pm 16 \%$ in Phase B and in Phase C, respectively. Firmicutes was the second most dominant phylum member in Phase A $(25 \pm 7 \%)$. The relative abundance of Firmicutes increased by bioaugmentation: it was $45 \pm 4 \%$ in Phase B and $38 \pm 11 \%$ in Phase C. In this regard, the bioaugmentation effect in each phase was more distinctly based on the relative abundance of family members (Figures 3B,D,F).

The bacterial community profile in the control reactor was presented in our recently published study (Atasoy and Cetecioglu, 2021). The results showed that the dominant phylum members changed through the reactor operation in the control reactor. Firmicutes $(30 \pm 3 \%)$ were dominant at the beginning of the reactor operation, while Bacteroidetes became dominant gradually, their relative abundance increased to $35 \pm 11$ and $49 \pm 13 \%$ after almost 4 and 21 weeks of reactor operation, respectively (Atasoy and Cetecioglu, 2021).

The most dominant family members were Flavobacteriaceae (15 $\pm 6 \%$ ) in Phase A; Thermoanaerobacterales Family III. Incertae sedis $(24 \pm 6 \%)$ in Phase B and Porphyromonadaceae $(14 \pm 7 \%)$ in Phase C, respectively in the bioaugmented reactor. On the other hand, the most dominant family members in the control reactor were Porphyromonadaceae (12 $\pm 2 \%$ ), Coriobacteriaceae $(8 \pm 3 \%)$, and Flavobacteriaceae $(8 \pm 5 \%)$ 


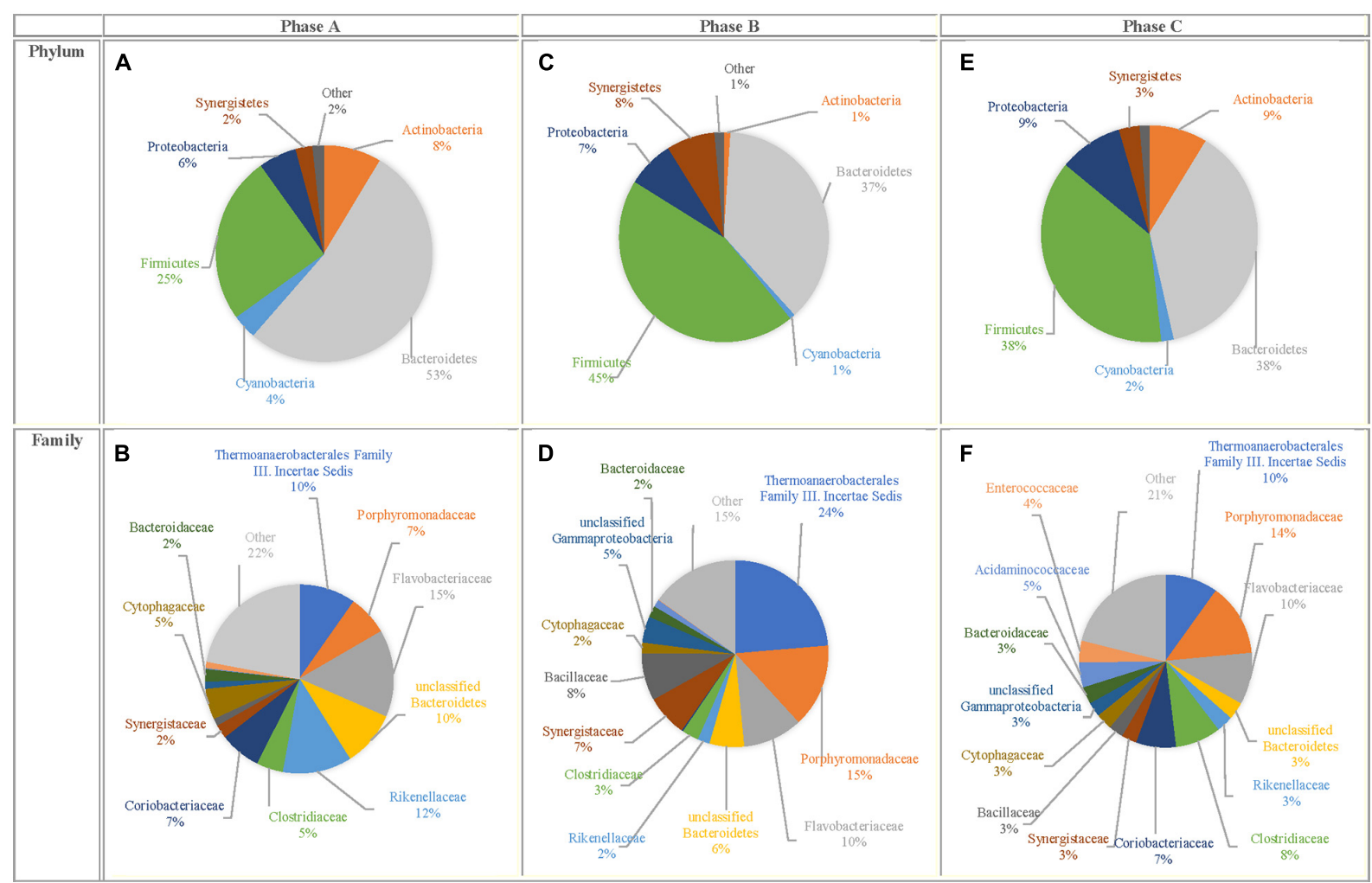

FIGURE 3 | Bacterial community profile for Phase A, Phase B, and Phase C for phylum level (A,C,E) and family level (B,D,F).

at the beginning of the reactor operation. After 21 weeks, Porphyromonadaceae $(27 \pm 12 \%)$, Bacteroidaceae $(17 \pm 4 \%)$, and Veillonellaceae $(11 \pm 3 \%)$ became dominant in the control reactor (Atasoy and Cetecioglu, 2021).

Thermoanaerobacterales Family III. Incertae sedis belongs to the Firmicutes phylum, main fermentation products are acetate, succinate, ethanol and formate (Gries et al., 2019). The results revealed that the relative abundance of Thermoanaerobacterales Family III. Incertae sedis increased simultaneously with the gene copy number of $C$. aceticum during bioaugmentation. From this point of view, despite that, there is no study in the literature about the relations between species of the Thermoanaerobacterales Family III. Incertae sedis and C. aceticum, the results of the current study suggest that there might be a syntropy for acetic acid production.

The relative abundance of Porphyromonadaceae, which is a family member of Bacteroidetes phylum, increased by bioaugmentation. Since Porphyromonadaceae is mainly responsible for propionic acid production (Rios-Covian et al., 2017), an increase in propionic acid production during and after bioaugmentation might link with the high abundance of Porphyromonadaceae. Furthermore, Porphyromonadaceae $(27 \pm 12 \%)$ was the most dominant family member in the control reactor at the end of the reactor operation (Atasoy and Cetecioglu, 2021).

The relative abundance of Rikenellaceae from the phylum of Bacteroidetes, dramatically decreased by bioaugmentation: it was
$12 \pm 3 \%$ in Phase $\mathrm{A} ; 2 \pm 0.7 \%$ in Phase $\mathrm{B}$, and $3 \pm 1.02 \%$ in Phase C. Apart from the effects of bioaugmentation, the relative abundance of Rikenellaceae decreased by the retention time in anaerobic digesters (Nakasaki et al., 2020). Rikenellaceae is a well-known species in anaerobic digesters (Koo et al., 2019; Nakasaki et al., 2020; Schwan et al., 2020) and participates in easily degradable compounds (i.e., glycerol) degradation to acetic acid in fermentation (Nakasaki et al., 2020). In the current study, the decreasing relative abundance of Rikenellaceae in Phase B and Phase $\mathrm{C}$ might be caused by either rapid consumption of readily biodegradable compounds or competing with $C$. aceticum and members of the Rikenellaceae family.

\section{Volatile Fatty Acid Composition Shift at the Bioaugmented Reactor}

The main aim of mixed culture bioaugmentation with C. aceticum was to enhance acetic acid production in the VFA mixture. As stated before, acetic acid concentration was increased by bioaugmentation by $C$. aceticum: the average acetic acid percentage in the VFA mixture was $8 \pm 0.2 \%$ in Phase A, $15 \pm 4 \%$ in Phase B and $22 \pm 5 \%$ in Phase C (Figure 4A). Interestingly, the results stated that the dominant acid type, which was propionic acid, did not change by bioaugmentation. Although C. aceticum is not responsible for propionic acid production according to its metabolic pathway (Alexander and Weuster-Botz, 2017; Arslan et al., 2019), propionic acid 
production was enhanced by bioaugmentation of C. aceticum. The average percentage propionic acid concentration in the VFA mixture was $34 \pm 23 \%$ in Phase A, $55 \pm 13 \%$ in Phase B, and $49 \pm 9 \%$ in Phase $C$. The dominant acid type was propionic acid in the control reactor during operation (Figure 4B). The acid composition in the control reactor as an average was: $59 \pm 12 \%$ propionic acid, $13 \pm 7 \%$ acetic acid, $8 \pm 3 \%$ isovaleric acid, $7 \pm 2 \%$ butyric acid, and $6 \pm 3 \%$ isobutyric acid. The results stated that despite the propionic acid was dominant at both reactors, the bioaugmentation of $C$. aceticum suppressed the propionic acid percentage in the VFA mixture, while it increased the ratio of acetic acid.

The manipulation of the operational conditions in mixed culture fermentation can affect the acid composition (Lu et al., 2011). Nevertheless, control of the manipulation mechanism depends on thermodynamic and metabolic principles: the product mixture is specified by thermodynamic constraints and enzyme availability in pure culture fermentation, while, it is more complicated in mixed culture fermentation because of the wide range of metabolic activities and energetic considerations (Mohd-Zaki et al., 2016). Many studies have been conducted to identify metabolic flux and energy conversions in mixed culture fermentation (Lee et al., 2008; Hoelzle et al., 2014; De Vrieze and Verstraete, 2016; Cetecioglu et al., 2019). Lee et al. (2008) evaluated $\mathrm{H}_{2}$ production from glucose fermentation under several pH conditions, thermodynamically (Lee et al., 2008). Based on their calculations, the standard Gibbs Free Energy $\left(\Delta \mathrm{G}^{\circ}\right)^{\prime}$ for acetic acid and propionic acid production via glucose fermentation under $\mathrm{pH} 10$ stated that acetic acid production has $-1,14 \mathrm{~kJ} / \mathrm{e}^{-}$; propionic acid production has $-6,78 \mathrm{~kJ} / \mathrm{e}^{-}$. Though thermodynamic calculations in fermentation depend on many parameters such as $\mathrm{pH}$, temperature, substrate composition, therefore available electron acceptors, etc., the rough estimate would be an explanation for high propionic acid production in the bioaugmented reactor since propionic acid production provides more energy than acetic acid production.

Besides acetic and propionic acid production, other acid type production during the operation were observed: the average acid composition during Phase $\mathrm{C}$ was composed of $11 \pm 8 \%$ of iso-valeric acid, $6 \pm 4 \%$ of valeric acid, $5 \pm 4 \%$ of isobutyric acid, and $5 \pm 3.2 \%$ of butyric acid in addition to acetic acid and propionic acid. Therefore, the bioaugmentation of C. aceticum enhanced not only acetic acid production but also increased propionic acid production indirectly and other acid productions (Alexander and Weuster-Botz, 2017). Nevertheless, the bioaugmentation of mixed culture by C. butyricum showed that the dominant acid type (propionic acid) was shifted to butyric acid by bioaugmentation (Atasoy and Cetecioglu, 2020). In addition, their results stated that bioaugmentation of C. butyricum did not only change dominant acid type but also significantly affect the VFA composition as well: propionic acid was decreased (from $60 \pm 12$ to $30 \pm 17 \%$ ) whereas, acetic (from $12 \pm 7$ to $20 \pm 11 \%$ ), butyric (from $21 \pm 9$ to $35 \pm 4 \%$ ), and valeric (from $8 \pm 4$ to $15 \pm 5 \%$ ) acids were increased by bioaugmentation (Atasoy and Cetecioglu, 2020). Therefore, despite pH (Atasoy et al., 2019b; Eryildiz et al., 2020), substrate type (Jankowska et al., 2017; Ma et al., 2017), and temperature
(Jiang et al., 2013; Vanwonterghem et al., 2015) affected the VFA composition, the current results showed that type of monoculture in bioaugmentation is also one of the important parameters to effect acid type in fermentation.

\section{Total VFA Production at the Bioaugmented Reactor}

The total VFA production in the bioaugmented reactor was $1204 \pm 340 \mathrm{mg}$ COD/L (0.67 gCOD/gCOD yield) at Phase A, $1878 \pm 338 \mathrm{mg}$ COD/L (0.79 gCOD/gCOD yield) at Phase B, and $4166 \pm 988 \mathrm{mg} \mathrm{COD} / \mathrm{L}$ (0,85 gCOD/gCOD yield) at Phase C. Also, the highest total VFA production was obtained at day 70 th as $5493 \pm 36 \mathrm{mg} \mathrm{COD} / \mathrm{L}$ with a $0,98 \mathrm{gCOD} / \mathrm{gCOD}$ production yield. In the control reactor, the average total VFA concentration was $1254 \pm 11 \mathrm{mg}$ COD/L with $0.68 \pm 0.02 \mathrm{gCOD} / \mathrm{gCOD}$ yield. Thus, based on the total VFA concentration in the bioaugmented and the control reactor, the average concentration increased 3.3 times, whereas the maximum concentration increased 5 times.

The efficiency of VFA production via fermentation depends on several operational and environmental conditions. Jankowska et al. (2017) showed the importance of substrate type on VFA production (Jankowska et al., 2017). Their results stated that the highest VFA was obtained from microalgae biomass (0.83 gVFA/gSCOD), maize silage (0.78 gVFA/gSCOD), and cheese whey (0.71 gVFA/gSCOD), respectively, under initial alkaline pH conditions. Moretto et al. (2019) investigated the optimized conditions for VFA production under mesophilic and thermophilic conditions with different $\mathrm{pH}$ values by using a batch reactor and continuously stirred tank reactor (CSTR) from urban waste fermentation (Moretto et al., 2019). Their results showed that the batch reactor and CSTR produced almost the same VFA concentration with thermal pretreatment under $\mathrm{pH}$ 9 (41 $\pm 2 \mathrm{gCOD} / \mathrm{L}$ for batch; $39 \mathrm{gCOD} / \mathrm{L}$ for CSTR). The $\mathrm{pH}$ did not affect VFA concentration $(\mathrm{pH}$ 9: $30 \pm 2 \mathrm{gCOD} / \mathrm{L}$; $\mathrm{pH} 7: 27.5 \pm 2 \mathrm{gCOD} / \mathrm{L}$ ) as well (Moretto et al., 2019). In addition, Atasoy et al. (2019b) confirmed that the $\mathrm{pH}$ had almost no effect on VFA production yield. From the point of parameters that affect VFA production, the results of the current study stated that the VFA production depends on the type of bacterial strain as well as their interactions with each other and their environment.

\section{The Correlation Analysis Between VFA Composition and Quantity of $C$. aceticum}

The concentration of each acid type and quantity of C. aceticum was correlated during fermentation (Phase $\mathrm{A}, \mathrm{B}$, and $\mathrm{C}$ ) to investigate their mutual effect on each other, the results are shown in Table 2. The correlation analysis results stated that acetic acid production positively correlated with total VFA (0.898), isovaleric acid (0.866), propionic acid (0.789), and iso-hexanoic acid (0.720) production at a 0.01 significance level as well as the gene copy number of $C$. aceticum $(0.553)$ at 0.05 significance level. Nevertheless, the bioaugmentation of C. aceticum resulted in higher propionic acid production in all phases. There was no correlation between propionic acid production and the gene copy number of $C$. aceticum. However, the total VFA 


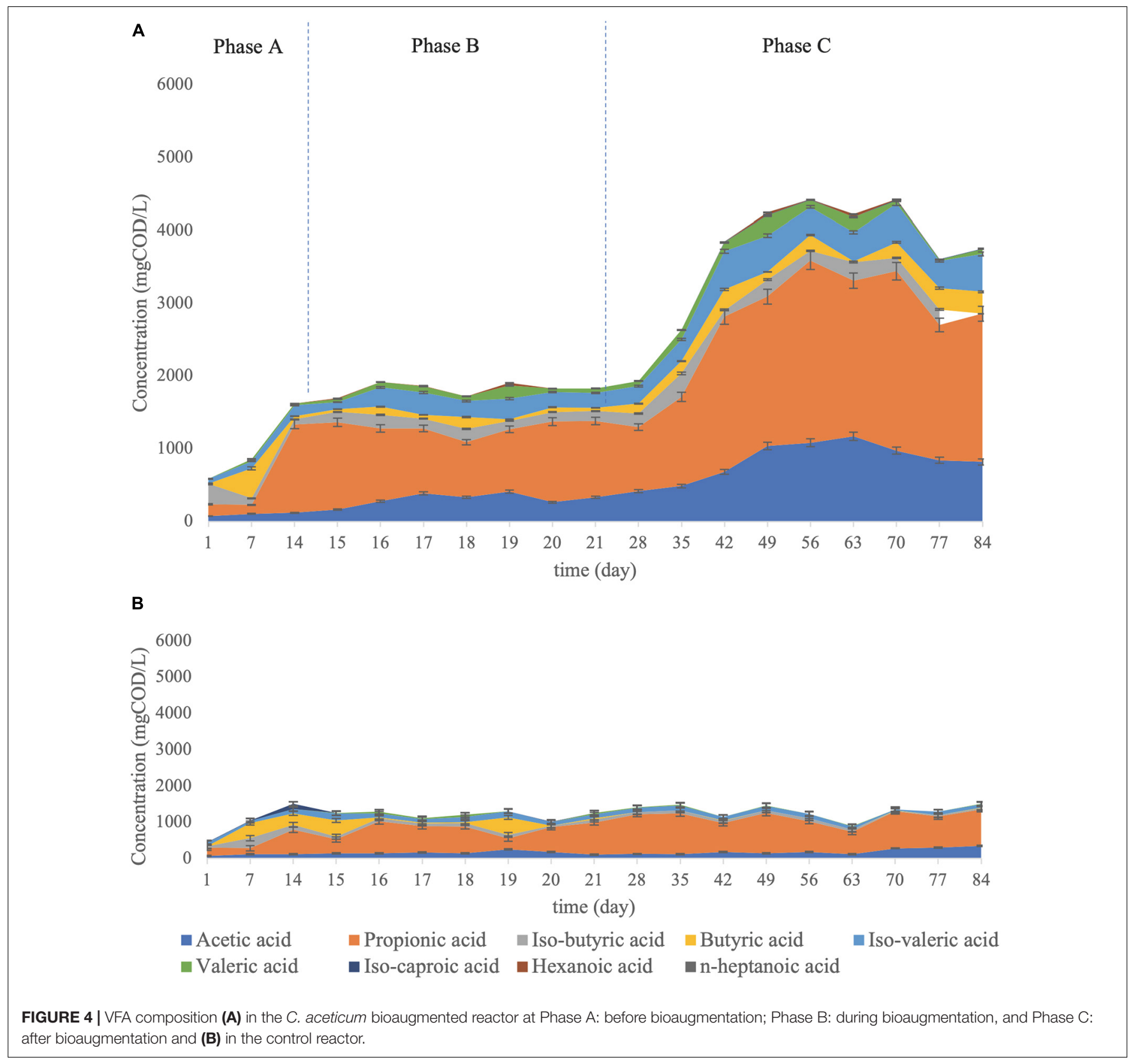

production was correlated (0.490 at 0.05 significance level) with C. aceticum. Therefore, the correlation analysis of $C$. aceticum bioaugmentation reactor data might be explained as $C$. aceticum enhanced propionic acid production indirectly.

\section{Cycle Analysis in the Bioaugmented Reactor}

The acid composition was observed during a cycle (24-hour) to investigate the acid shift. Therefore, the cycle analysis was conducted after seven days of bioaugmentation application (day 28). The acid shift during a cycle for the bioaugmented reactor is represented in Figure 5.
The cycle analysis of C. aceticum in the bioaugmented reactor showed that almost all acid types were increased to the peak point in the first $5 \mathrm{~h}$, then it was stable until the 9th hour. From the 13th hour, the production was increased again until at the end of the cycle. Mainly, acetic acid production in the 1st hour was $279 \pm 17 \mathrm{mg} \mathrm{COD} / \mathrm{L}$, then it increased in the first $3 \mathrm{~h}$ to $1157 \pm 29 \mathrm{mg} \mathrm{COD} / \mathrm{L}$. Following this, the production was almost stable in the next $14 \mathrm{~h}$; afterwards, it reached $1148 \pm 36 \mathrm{mg}$ $\mathrm{COD} / \mathrm{L}$ at the 24th hour. Propionic acid, which was the dominant acid type during a cycle, started from $1859 \pm 204 \mathrm{mg}$ COD/L in the 1st hour. It reached $3465 \pm 108 \mathrm{mg} \mathrm{COD} / \mathrm{L}$ at the end of the cycle (24th hour), although the highest propionic acid concentration was between the 5 th and 9 th hours. 
TABLE 2 | Correlation coefficients between the quantification of $C$. aceticum with VFA composition after bioaugmentation.

\begin{tabular}{|c|c|c|c|c|c|c|c|c|c|c|c|}
\hline & $\begin{array}{l}\text { Acetic } \\
\text { acid }\end{array}$ & $\begin{array}{l}\text { Propionic } \\
\text { acid }\end{array}$ & $\begin{array}{l}\text { Iso-butyric } \\
\text { acid }\end{array}$ & $\begin{array}{c}\text { Butyric } \\
\text { acid }\end{array}$ & $\begin{array}{l}\text { Iso-valeric } \\
\text { acid }\end{array}$ & $\begin{array}{c}\text { Valeric } \\
\text { acid }\end{array}$ & $\begin{array}{l}\text { Iso hexanoic } \\
\text { acid }\end{array}$ & $\begin{array}{c}\text { Hexanoic } \\
\text { acid }\end{array}$ & $\begin{array}{c}\text { n-heptanic } \\
\text { acid }\end{array}$ & $\begin{array}{l}\text { Total } \\
\text { VFA }\end{array}$ & $\begin{array}{l}\text { C.aceticum } \\
\text { copy number }\end{array}$ \\
\hline Acetic acid & 1 & $0.789^{\star \star}$ & 0.312 & 0.012 & $0.866^{\star \star}$ & $0.542^{\star}$ & $0.720^{\star *}$ & 0.424 & $0.551^{*}$ & $0.898^{\star \star}$ & $0.553^{\star}$ \\
\hline Iso-butyric acid & 0.312 & 0.226 & 1 & $0.476^{\star}$ & $0.471^{*}$ & -0.095 & $0.583^{\star *}$ & -0.217 & 0.426 & 0.361 & 0.194 \\
\hline Butyric acid & 0.012 & 0.013 & $0.476^{\star}$ & 1 & 0.073 & -0.402 & 0.403 & $-0.468^{\star}$ & 0.058 & 0.109 & -0.33 \\
\hline Iso-valeric acid & $0.866^{\star \star}$ & $0.878^{\star \star}$ & $0.471^{*}$ & 0.073 & 1 & $0.489^{\star}$ & $0.729^{\star *}$ & 0.277 & 0.406 & $0.943^{\star \star}$ & $0.646^{\star \star}$ \\
\hline $\begin{array}{l}\text { Iso hexanoic } \\
\text { acid }\end{array}$ & $0.720^{\star \star}$ & $0.770^{\star *}$ & $0.583^{\star \star}$ & 0.403 & $0.729^{\star \star}$ & -0.023 & 1 & 0.01 & 0.292 & $0.816^{\star \star}$ & 0.233 \\
\hline Hexanoic acid & 0.424 & 0.383 & -0.217 & $-0.468^{\star}$ & 0.277 & $0.837^{\star \star}$ & 0.01 & 1 & 0.151 & 0.379 & 0.173 \\
\hline $\begin{array}{l}\text { n-heptanoic } \\
\text { acid }\end{array}$ & $0.551^{*}$ & 0.197 & 0.426 & 0.058 & 0.406 & 0.329 & 0.292 & 0.151 & 1 & 0.355 & 0.177 \\
\hline Total VFA & $0.898^{\star \star}$ & $0.968^{* *}$ & 0.361 & 0.109 & $0.943^{\star \star}$ & $0.483^{*}$ & $0.816^{\star *}$ & 0.379 & 0.355 & 1 & $0.490^{*}$ \\
\hline
\end{tabular}

${ }^{* *}$ Correlation is significant at the 0.01 level (2-tailed); ${ }^{*}$ Correlation is significant at the 0.05 level (2-tailed).

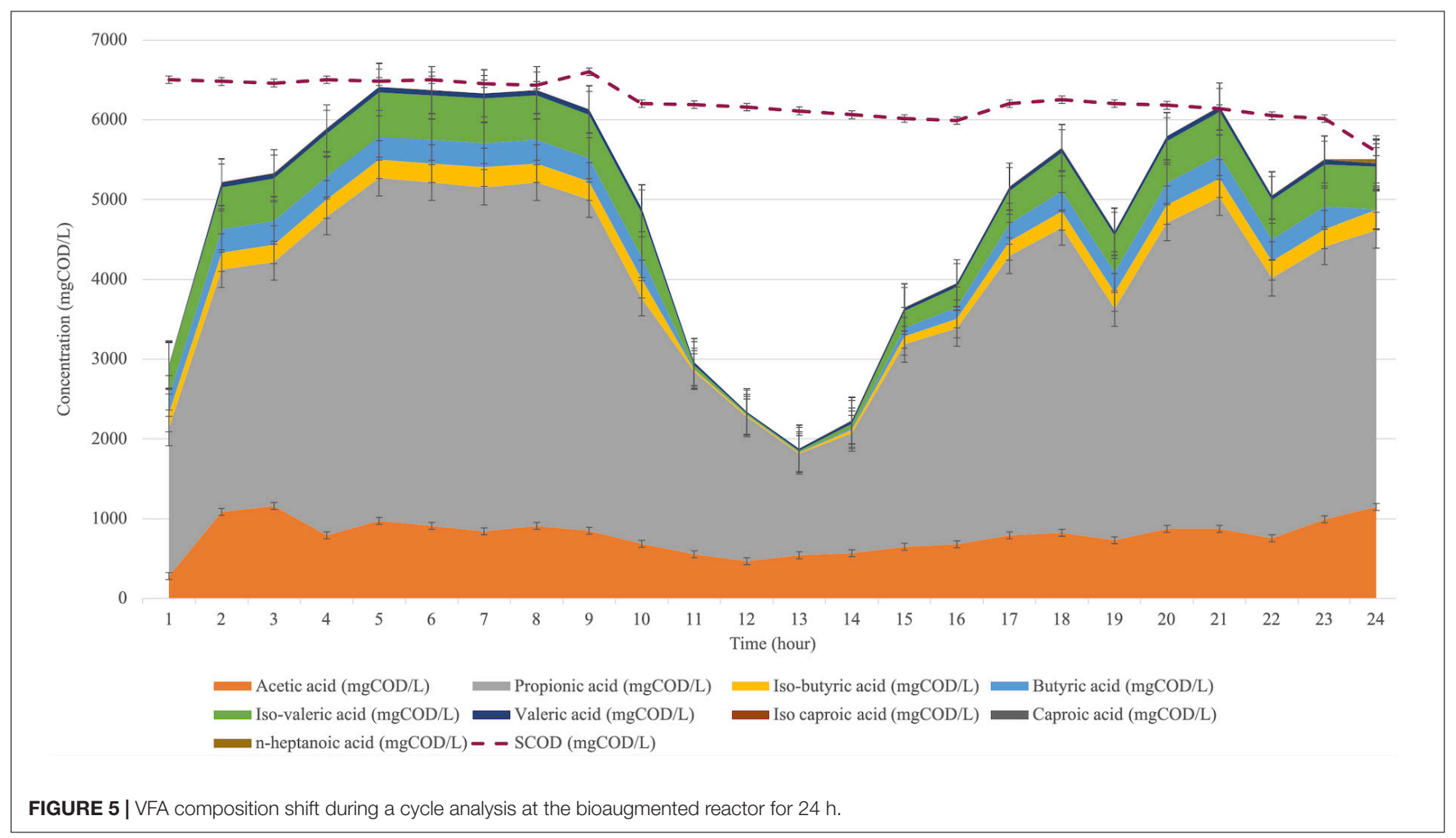

The sCOD concentration from the 1st hour to the 24th hour (Figure 5) showed that the SCOD reduction was negligible. Nevertheless, the reason for the drop in total VFA production between the 11th and 17th hours could be explained by $\mathrm{CO}_{2}$ production. On the other hand, as described previously, the metabolic pathway of C. aceticum has reversible reactions from acetic acid to ethanol production as well as vice versa (Grimalt-Alemany et al., 2018). Therefore, the results might be explained by chain elongation (De Groof et al., 2019) from short-chain fatty acids (VFA) to medium or large chain fatty acids as well as ethanol or $\mathrm{CO}_{2}$ production after the 16th hour. Following this, the reversible reactions might have increased VFA production again from the 14th hour. The cycle analysis stated that the highest VFA production, as well as acetic acid concentration, could be obtained in the first $6 \mathrm{~h}$ of the cycle, shortening the retention time or reduction of the reactor volume. In addition, cycle analysis was also conducted in the control reactor. The results showed that $12 \mathrm{~h}$ would be sufficient as a cycle duration to achieve a similar VFA 
composition and production efficiency in the control reactor (Atasoy and Cetecioglu, 2020).

\section{CONCLUSION}

In this study, mixed microbial culture was bioaugmented by $C$. aceticum to obtain an acetic acid dominant VFA mixture. Despite the fact that acetic acid concentration was increased by bioaugmentation (almost 10-fold compared to the control reactor), the dominance of the propionic acid in the VFA mixture did not change. However, the effects of the bioaugmentation indicate certain unknown syntrophic relations and corresponding metabolic pathways. It is crucial to gain a deeper understanding of bioaugmentation's effects on the microbial community, particularly to establish its profile and the functions and interactions in the mixed culture. Furthermore, the identification of metabolic networks for acid production is crucial for a comprehensive view of bioaugmentation effects.

\section{DATA AVAILABILITY STATEMENT}

The datasets presented in this study can be found in online repositories. The names of the repository/repositories and

\section{REFERENCES}

Alexander, M., and Weuster-Botz, D. (2017). Reaction engineering analysis of the autotrophic energy metabolism of Clostridium aceticum. Biochem. Eng. J. 364:fnx219. doi: 10.1093/femsle/fnx219

Allied Market Research (2020). World Acetic Acid Market - Opportunities and Forecasts, 2019-2026. Available online at: https://www.alliedmarketresearch. com/acetic-acid-market (accessed March 20, 2020).

APHA, AWWA, and WEF (2012). Standard Methods for the Examination of Water and Wastewater. Stand Methods. Alexandria, VA: Water Environment Federation, 541.

Arslan, K., Bayar, B., Nalakath Abubackar, H., Veiga, M. C., and Kennes, C. (2019). Solventogenesis in Clostridium aceticum producing high concentrations of ethanol from syngas. Bioresour. Technol. 292, 121941. doi: 10.1016/j.biortech. 2019.121941

Atasoy, M., and Cetecioglu, Z. (2020). Butyric acid dominant volatile fatty acids production: bio-augmentation of mixed culture fermentation by Clostridium butyricum. J. Environ. Chem. Eng. 8:104496. doi: 10.1016/j.jece.2020.104496

Atasoy, M., and Cetecioglu, Z. (2021). Bioaugmentation as a strategy for tailormade volatile fatty acid production. J. Environ. Manage 295:113093.

Atasoy, M., Eyice, Ö, and Cetecioglu, Z. (2019a). Volatile fatty acid production from semi-synthetic milk processing wastewater under alkali $\mathrm{pH}$ : the pearls and pitfalls of microbial culture. Bioresour. Technol. 19:122415. doi: 10.1016/ j.biortech.2019.122415

Atasoy, M., Eyice, Ö., and Cetecioglu, Z. (2020a). A comprehensive study of volatile fatty acids production from batch reactor to anaerobic sequencing batch reactor by using cheese processing wastewater. Bioresour. Technol. 311:123529. doi: 10.1016/j.biortech.2020.123529

Atasoy, M., Eyice, O., Schnürer, A., and Cetecioglu, Z. (2019b). Volatile fatty acids production via mixed culture fermentation: revealing the link between $\mathrm{pH}$, inoculum type and bacterial composition. Bioresour. Technol. 292:121889. doi: 10.1016/j.biortech.2019.121889

Atasoy, M., Owusu-Agyeman, I., Plaza, E., and Cetecioglu, Z. (2018). Bio-based volatile fatty acid production and recovery from waste streams: current status and future challenges. Bioresour. Technol. 268, 0-1. doi: 10.1016/j.biortech. 2018.07.042 accession number(s) can be found below: https://www.ncbi.nlm. nih.gov/, PRJNA667606.

\section{AUTHOR CONTRIBUTIONS}

MA: conceptualization, methodology, formal analysis, investigation, data curation, writing - original draft, and visualization. ZC: conceptualization, writing - review and editing, and supervision. Both authors contributed to the article and approved the submitted version.

\section{FUNDING}

This study was financed by the Vinnmer Marie Curie Incoming Grant (2016-04070).

\section{ACKNOWLEDGMENTS}

We would like to acknowledged support from the Science for Life Laboratory, the National Genomics Infrastructure, NGI, and Uppmax for assisting in massive parallel sequencing and computational infrastructure.

Bhatia, S. K., and Yang, Y.-H. (2017). Microbial production of volatile fatty acids: current status and future perspectives. Rev. Environ. Sci. Bio Technol. 16, 327-345. doi: 10.1007/s11157-017-9431-4

Braun, M., Mayer, F., and Gottschalk, G. (1981). Clostridium aceticum (Wieringa), a microorganism producing acetic acid from molecular hydrogen and carbon dioxide. Arch. Microbiol. 128, 288-293. doi: 10.1007/BF00422532

Britz, T. J., and van Schalkwyk, C. (2006). Treatment of dairy processing wastewaters. Waste Treat. Food Process. Ind. 6, 1-28. doi: 10.1201/ 9781420037128.ch1

Caporaso, J. G., Lauber, C. L., Walters, W. A., Berg-Lyons, D., Lozupone, C. A., Turnbaugh, P. J., et al. (2011). Global patterns of 16 S rRNA diversity at a depth of millions of sequences per sample. Proc. Natl. Acad. Sci. U.S.A. 108, 4516-4522. doi: 10.1073/pnas.1000080107

Cetecioglu, Z., Dolfing, J., Taylor, J., Purdy, K. J., and Eyice, Ö (2019). COD/sulfate ratio does not affect the methane yield and microbial diversity in anaerobic digesters. Water Res. 155, 444-454. doi: 10.1016/j.watres.2019.02.038

Chi, X., Li, J., Wang, X., Zhang, Y., Leu, S. Y., and Wang, Y. (2018). Bioaugmentation with Clostridium tyrobutyricum to improve butyric acid production through direct rice straw bioconversion. Bioresour. Technol. 263, 562-568. doi: 10.1016/j.biortech.2018.04.120

Ciesielski, S., and Przybylek, G. (2014). Volatile fatty acids influence on the structure of microbial communities producing PHAs. Brazilian J. Microbiol. 45, 395-402. doi: 10.1590/S1517-83822014000200005

Cirne, D. G., Björnsson, L., Alves, M., and Mattiasson, B. (2006). Effects of bioaugmentation by an anaerobic lipolytic bacterium on anaerobic digestion of lipid-rich waste. J. Chem. Technol. Biotechnol. 81, 1745-1752. doi: 10.1002/ jctb. 1597

Cock, P. J. A., Antao, T., Chang, J. T., Chapman, B. A., Cox, C. J., Dalke, A., et al. (2009). Biopython: Freely available Python tools for computational molecular biology and bioinformatics. Bioinformatics 25, 1422-1423. doi: 10 . 1093/bioinformatics/btp163

De Groof, V., Coma, M., Arnot, T., Leak, D. J., and Lanham, A. B. (2019). Medium chain carboxylic acids from complex organic feedstocks by mixed culture fermentation. Molecules 24, 1-39. doi: 10.3390/molecules24030398

De Vrieze, J., and Verstraete, W. (2016). Perspectives for microbial community composition in anaerobic digestion: from abundance and activity to 
connectivity. Environ. Microbiol. 18, 2797-2809. doi: 10.1111/1462-2920.13 437

Dietrich, K., Dumont, M. J., Del Rio, L. F., and Orsat, V. (2017). Producing PHAs in the bioeconomy - Towards a sustainable bioplastic. Sustain. Prod. Consum. 9, 58-70. doi: 10.1016/j.spc.2016.09.001

Du, R., Peng, Y., Ji, J., Shi, L., Gao, R., and Li, X. (2019). Partial denitrification providing nitrite: opportunities of extending application for anammox. Environ. Int. 131:105001. doi: 10.1016/j.envint.2019.105001

Eryildiz, B., Lukitawesa, and Taherzadeh, M. J. (2020). Effect of pH, substrate loading, oxygen, and methanogens inhibitors on volatile fatty acid (VFA) production from citrus waste by anaerobic digestion. Bioresour. Technol. 302:122800. doi: 10.1016/j.biortech.2020.122800

Eurostat (2020). Chemicals production and consumption statistics. Stat. Explain. 2009, 1-9.

Expert Market Research (2019). Global Acetic Acid Market. Sheridan, WY: Expert Market Research.

Fang, W., Zhang, X., Zhang, P., Wan, J., Guo, H., Ghasimi, D. S. M., et al. (2020). Overview of key operation factors and strategies for improving fermentative volatile fatty acid production and product regulation from sewage sludge. J. Environ. Sci. (China) 87, 93-111. doi: 10.1016/j.jes.2019.05.027

FDA (1989). Available online at: https://www.fda.gov/regulatory-information/ search-fda-guidance-documents/cpg-sec-562100-acetic-acid-use-foodslabeling-foods-which-used (accessed March 20, 2020).

Greses, S., Tomás-Pejó, E., and Gónzalez-Fernández, C. (2020). Agroindustrial waste as a resource for volatile fatty acids production via anaerobic fermentation. Bioresour. Technol. 297, 122486. doi: 10.1016/j.biortech.2019. 122486

Gries, O., Ly, T., Gries, O., and Ly, T. (2019). The Firmicutes, Bergey's Manual of Systematic Bacteriology, 2nd Edn. Salmon Tower Building: Springer International Publishing. doi: 10.1007/978-3-662-58219-0_26

Grimalt-Alemany, A., Łęzyk, M., Lange, L., Skiadas, I. V., and Gavala, H. N. (2018). Enrichment of syngas-converting mixed microbial consortia for ethanol production and thermodynamics-based design of enrichment strategies. Biotechnol. Biofuels 11, 1-22. doi: 10.1186/s13068-018-1189-6

Gunjan, D., and Haresh, M. (2020). Production pathways of acetic acid and its versatile applications in the food industry. Intech 32, 137-144. doi: 10.5772/ intechopen.92289

Hansen, R. G. (1974). “Milk in human nutrition," in Nutrition and Biochemistry of Milk/Maintenance, eds B. L. Larson and V. R. SMITH (Academic Press), doi: 10.1016B978-0-12-436703-6.50013-2

Herrero, M., and Stuckey, D. C. (2015). Bioaugmentation and its application in wastewater treatment: a review. Chemosphere 140, 119-128. doi: 10.1016/j. chemosphere.2014.10.033

Hoelzle, R. D., Virdis, B., and Batstone, D. J. (2014). Regulation mechanisms in mixed and pure culture microbial fermentation. Biotechnol. Bioeng. 111, 2139-2154. doi: 10.1002/bit.25321

Hong, P., Wu, X., Shu, Y., Wang, C., Tian, C., Wu, H., et al. (2020). Bioaugmentation treatment of nitrogen-rich wastewater with a denitrifier with biofilm-formation and nitrogen-removal capacities in a sequencing batch biofilm reactor. Bioresour. Technol. 303:122905. doi: 10.1016/j.biortech.2020. 122905

Jankowska, E., Chwialkowska, J., Stodolny, M., and Oleskowicz-Popiel, P. (2017). Volatile fatty acids production during mixed culture fermentation - The impact of substrate complexity and pH. Chem. Eng. J. 326, 901-910. doi: 10.1016/j.cej. 2017.06.021

Jiang, J., Zhang, Y., Li, K., Wang, Q., Gong, C., and Li, M. (2013). Volatile fatty acids production from food waste: effects of $\mathrm{pH}$, temperature, and organic loading rate. Bioresour. Technol. 143, 525-530. doi: 10.1016/j.biortech.2013.06.025

Jones, S. W., Fast, A. G., Carlson, E. D., Wiedel, C. A., Au, J., Antoniewicz, M. R., et al. (2016). CO 2 fixation by anaerobic non-photosynthetic mixotrophy for improved carbon conversion. Nat. Commun. 7:12800. doi: 10.1038/ ncomms 12800

Kedia, G., Passanha, P., Dinsdale, R. M., Guwy, A. J., and Esteves, S. R. (2014). Evaluation of feeding regimes to enhance PHA production using acetic and butyric acids by a pure culture of Cupriavidus necator. Biotechnol. Bioprocess Eng. 19, 989-995. doi: 10.1007/s12257-014-0144-z

Khan, M. A., Ngo, H. H., Guo, W. S., Liu, Y., Nghiem, L. D., Hai, F. I., et al. (2016a). Optimization of process parameters for production of volatile fatty acid, biohydrogen and methane from anaerobic digestion. Bioresour. Technol. 219, 738-748. doi: 10.1016/j.biortech.2016.08.073

Khan, M. A., Ngo, H. H., Guo, W. S., Liu, Y. W., Zhou, J. L., Zhang, J., et al. (2016b). Comparing the value of bioproducts from different stages of anaerobic membrane bioreactors. Bioresour. Technol. 214, 816-825. doi: 10. 1016/j.biortech.2016.05.013

Klindworth, A., Pruesse, E., Schweer, T., Peplies, J., Quast, C., Horn, M., et al. (2013). Evaluation of general 16S ribosomal RNA gene PCR primers for classical and next-generation sequencing-based diversity studies. Nucleic Acids Res. 41, 1-11. doi: $10.1093 /$ nar/gks 808

Koo, T., Yulisa, A., and Hwang, S. (2019). Microbial community structure in full scale anaerobic mono-and co-digesters treating food waste and animal waste. Bioresour. Technol. 282, 439-446. doi: 10.1016/j.biortech.2019.03.050

Küsel, K., and Drake, H. L. (2011). “Acetogens,” in Encyclopedia of Geobiology, eds R. Joachim and T. Volker (Berlin: Springer), 928. doi: 10.1007/978-1-40209212-1

Lagoa-Costa, B., Kennes, C., and Veiga, M. C. (2020). Cheese whey fermentation into volatile fatty acids in an anaerobic sequencing batch reactor. Bioresour. Technol. 302, 5175-5181. doi: 10.1016/j.watres.2020.115633

Lee, H. S., Salerno, M. B., and Rittmann, B. E. (2008). Thermodynamic evaluation on H2 production in glucose fermentation. Environ. Sci. Technol. 42, 24012407. doi: 10.1021/es702610v

Li, Y., Zhang, Q., Li, M., Sang, W., Wang, Y., Wu, L., et al. (2020). Bioaugmentation of sequencing batch reactor for aniline treatment during start-up period: Investigation of microbial community structure of activated sludge. Chemosphere 243:125426. doi: 10.1016/j.chemosphere.2019.125426

Lim, J. X., Zhou, Y., and Vadivelu, V. M. (2020). Enhanced volatile fatty acid production and microbial population analysis in anaerobic treatment of high strength wastewater. J. Water Process Eng. 33:101058. doi: 10.1016/j.jwpe.2019. 101058

Lu, H., Villada, J. C., and Lee, P. K. H. (2019). Modular metabolic engineering for biobased chemical production. Trends Biotechnol. 37, 152-166. doi: 10.1016/j. tibtech.2018.07.003

Lu, Y., Slater, F. R., Mohd-Zaki, Z., Pratt, S., and Batstone, D. J. (2011). Impact of operating history on mixed culture fermentation microbial ecology and product mixture. Water Sci. Technol. 64, 760-765. doi: 10.2166/wst.2011.699

Ma, H., Liu, H., Zhang, L., Yang, M., Fu, B., and Liu, H. (2017). Novel insight into the relationship between organic substrate composition and volatile fatty acids distribution in acidogenic co-fermentation. Biotechnol. Biofuels 10, 1-15. doi: 10.1186/s13068-017-0821-1

Mielcarek, A., Rodziewicz, J., Janczukowicz, W., and Bryszewski, K. (2018). Effect of acetic acid on denitrification and dephosphatation process efficiencies in sequencing batch biofilm reactor. J. Ecol. Eng. 19, 176-180. doi: 10.12911/ 22998993/89659

Mohd-Zaki, Z., Bastidas-Oyanedel, J., Lu, Y., Hoelzle, R., Pratt, S., Slater, F., et al. (2016). Influence of $\mathrm{pH}$ regulation mode in glucose fermentation on product selection and process stability. Microorganisms 4:2. doi: 10.3390/ microorganisms 4010002

Moretto, G., Valentino, F., Pavan, P., Majone, M., and Bolzonella, D. (2019). Optimization of urban waste fermentation for volatile fatty acids production. Waste Manag. 92, 21-29. doi: 10.1016/j.wasman.2019.05.010

Mussatto, S. I. (2017). Challenges in building a sustainable biobased economy. Ind. Crops Prod. 106, 1-2. doi: 10.1016/j.indcrop.2017.07.007

Nakasaki, K., Nguyen, K. K., Ballesteros, F. C., Maekawa, T., and Koyama, M. (2020). Characterizing the microbial community involved in anaerobic digestion of lipid-rich wastewater to produce methane gas. Anaerobe 61:102082. doi: 10.1016/j.anaerobe.2019.102082

OECD (2003). Guideline For The Testing of Chemicals Proposal. Paris: Organisation for Economic Co-operation and Development.

Poehlein, A., Cebulla, M., Ilg, M. M., Bengelsdorf, F. R., Schiel-bengelsdorf, B., Whited, G., et al. (2015). The complete genome sequence of clostridium aceticum: a missing. MBio 6:e01168-15. doi: 10.1128/mBio.01168-15.Editor

Riegler, P., Bieringer, E., Chrusciel, T., Stärz, M., Löwe, H., and Weuster-Botz, D. (2019). Continuous conversion of $\mathrm{CO} 2 / \mathrm{H} 2$ with Clostridium aceticum in biofilm reactors. Bioresour. Technol. 291:121760. doi: 10.1016/j.biortech.2019. 121760

Rios-Covian, D., Salazar, N., Gueimonde, M., and de los Reyes-Gavilan, C. G. (2017). Shaping the metabolism of intestinal Bacteroides population through 
diet to improve human health. Front. Microbiol. 8:1-6. doi: 10.3389/fmicb.2017. 00376

Ritchie, H., and Roser, M. (2019). CO2 and Greenhouse Gas Emissions. Our World Data. Available online at: https://ourworldindata.org/co2-and-othergreenhouse-gas-emissions (accessed March 20, 2020).

Schwan, B., Abendroth, C., Latorre-Pérez, A., Porcar, M., Vilanova, C., and Dornack, C. (2020). Chemically stressed bacterial communities in anaerobic digesters exhibit resilience and ecological flexibility. Front. Microbiol. 11:867. doi: 10.3389/fmicb.2020.00867

She, Y., Hong, J., Zhang, Q., Chen, B. Y., Wei, W., and Xin, X. (2020). Revealing microbial mechanism associated with volatile fatty acids production in anaerobic acidogenesis of waste activated sludge enhanced by freezing/thawing pretreatment. Bioresour. Technol. 302:122869. doi: 10.1016/j.biortech.2020. 122869

Sim, J. H., Kamaruddin, A. H., Long, W. S., and Najafpour, G. (2007). Clostridium aceticum-A potential organism in catalyzing carbon monoxide to acetic acid: application of response surface methodology. Enzyme Microb. Technol. 40, 1234-1243. doi: 10.1016/j.enzmictec.2006.09.017

Tabatabaei, M., Aghbashlo, M., Valijanian, E., Kazemi Shariat Panahi, H., Nizami, A. S., Ghanavati, H., et al. (2020). A comprehensive review on recent biological innovations to improve biogas production, Part 2: mainstream and downstream strategies. Renew. Energy 146, 1392-1407. doi: 10.1016/j.renene.2019.07. 047

Talabardon, M., Schwitzguébel, J. P., and Péringer, P. (2000). Anaerobic thermophilic fermentation for acetic acid production from milk permeate. J. Biotechnol. 76, 83-92. doi: 10.1016/S0168-1656(99)00180-7

Tang, H., Zhang, Y., Hu, J., Li, Y., Li, N., and Wang, M. (2019). Mixture of different Pseudomonas aeruginosa SD-1 strains in the efficient bioaugmentation for synthetic livestock wastewater treatment. Chemosphere 237, 1-8. doi: 10 . 1016/j.chemosphere.2019.124455

UNEP (2013). Global Chemicals Outlook: Towards Sound Management of Chemicals. Nairobi: UNEP.

UNFCCC (2015). Paris Agreement. Conf. Parties Its Twenty-First Sess, Vol. 32. Rio de Janeiro: UNFCCC.

United Nations (2018). Sustainable Development Goals. Available online at: https: //sustainabledevelopment.un.org/sdgs (accessed March 20, 2020).

Vanwonterghem, I., Jensen, P. D., Rabaey, K., and Tyson, G. W. (2015). Temperature and solids retention time control microbial population dynamics and volatile fatty acid production in replicated anaerobic digesters. Sci. Rep. 5 , 1-8. doi: 10.1038/srep08496
Vidra, A., and Németh, Á (2018). Bio-produced acetic acid: a review. Period. Polytech. Chem. Eng. 62, 245-256. doi: 10.3311/PPch.11004

Wu, M., Guo, X., Wu, J., and Chen, K. (2020). Effect of compost amendment and bioaugmentation on PAH degradation and microbial community shifting in petroleum-contaminated soil. Chemosphere 256:126998. doi: 10.1016/j. chemosphere.2020.126998

Xie, J., Duan, X., Feng, L., Yan, Y., Wang, F., Dong, H., et al. (2019). Influence of sulfadiazine on anaerobic fermentation of waste activated sludge for volatile fatty acids production: focusing on microbial responses. Chemosphere 219, 305-312. doi: 10.1016/j.chemosphere.2018.12.015

Xu, K., Liu, H., Du, G., and Chen, J. (2009). Real-time PCR assays targeting formyltetrahydrofolate synthetase gene to enumerate acetogens in natural and engineered environments. Anaerobe 15, 204-213. doi: 10.1016/j.anaerobe.2009. 03.005

Yang, Z., Wang, W., Liu, C., Zhang, R., and Liu, G. (2019). Mitigation of ammonia inhibition through bioaugmentation with different microorganisms during anaerobic digestion: Selection of strains and reactor performance evaluation. Water Res. 155, 214-224. doi: 10.1016/j.watres.2019.02.048

Younes, M., Aquilina, G., Castle, L., Engel, K. H., Fowler, P., Frutos Fernandez, M. J., et al. (2020). Re-evaluation of acetic acid, lactic acid, citric acid, tartaric acid, mono- and diacetyltartaric acid, mixed acetic and tartaric acid esters of mono- and diglycerides of fatty acids (E 472a-f) as food additives. EFSA J. 18:6032. doi: $10.2903 /$ j.efsa.2020.6032

Conflict of Interest: The authors declare that the research was conducted in the absence of any commercial or financial relationships that could be construed as a potential conflict of interest.

Publisher's Note: All claims expressed in this article are solely those of the authors and do not necessarily represent those of their affiliated organizations, or those of the publisher, the editors and the reviewers. Any product that may be evaluated in this article, or claim that may be made by its manufacturer, is not guaranteed or endorsed by the publisher.

Copyright (c) 2021 Atasoy and Cetecioglu. This is an open-access article distributed under the terms of the Creative Commons Attribution License (CC BY). The use, distribution or reproduction in other forums is permitted, provided the original author(s) and the copyright owner(s) are credited and that the original publication in this journal is cited, in accordance with accepted academic practice. No use, distribution or reproduction is permitted which does not comply with these terms. 